\title{
Monetary Policy, Investors' Attention and the Dynamic Evolution of RMB Exchange Rate*
}

\author{
Xiuli Du \\ School of Finance \\ Nanjing University of Finance \& Economics \\ Nanjing, China 210023
}

\author{
Zhenzhen Ye \\ School of Finance \\ Nanjing University of Finance \& Economics \\ Nanjing, China 210023
}

\begin{abstract}
In recent years, the development of behavioral economics pointed out that the premise of investor behavior is investors' attention. Therefore, investor attention is an important channel through which monetary policy affects exchange rate. Consequently, it is necessary to study the relationship between monetary policy and exchange rate from the perspective of investors. This paper uses the Baidu index to construct the investor's attention index on monetary policy, and empirically analyzes the relationship between investors' attention and RMB exchange rate through the VAR model. The research results show that investors focusing on monetary policy can significantly positive influence on the RMB exchange rate changes, and the effect of investors' attention on exchange rate changes is independent of the control variables. By discussing monetary policy level of investor attention and associated characteristics of RMB exchange rate, this paper extends the research of investor attention on the foreign exchange market, provides reference for better implementation of monetary policy, and offers a new train of thought for exchange rate determination.
\end{abstract}

Keywords—RMB exchange rate; monetary policy; investors' attention

\section{INTRODUCTION}

As we all know, the development trend of economic globalization is irreversible, and its development process has been advancing continuously. While, financial globalization is an important part of economic globalization and a key and sensitive link in the world economic development. With the unceasing expanding in scales of trade, investment and capital flows between countries, the global link between financial activities and financial risks becomes tighter and tighter. Foreign exchange is inevitably used in trade on international commodity market and financial market so that exchange rate decision mechanism attracts highly attention of each country. Nowadays, China is one of the major economic powers in the world. RMB's participation in the SDR currency basket has further enhanced the international influence of the RMB. Exchange rate of RMB has not only

*CLC number: Document code: A

This paper was funded by the "Resource Misallocation in Jiangsu Province: Financial friction or Policy Distortion?" (Project No. 2017ZDIXM067) of universities' philosophy and social science researches project in Jiangsu Province, and “A study on Government's Intervention and System Risk in China's Stock Market” of Jiangsu Modern Service Industry Collaborative Innovation Center. received the attention of Chinese government, but has also received global attention.

Exchange rate change has a broad impact on the economy. Taking depreciation as an example: when local currency depreciates, the price of domestic exports is reduced so that it is beneficial to expand exports and improve the international payments situation; if it is predicted that local currency will depreciate continuously, funds will be transferred abroad so that international capital flow will be affected; the depreciation of local currency may cause reduction in international reserve value of the country; the depreciation may also affect other domestic economic indicators such as price of commodities and interest rate; the depreciation in currency of major industrial country may have significant impact on the economies of trade partner countries and further lead to trade wars and currency wars; in addition, unstable exchange rate for currency of great power may also pose enormous risk to the international financial system. Just because exchange rate change has such a significant impact on economy and finance, even countries executing floating exchange rate system may also formulate monetary policy to interfere with foreign exchange market in order to get exchange rate stabilized within certain range. Monetary policy often targets to realize domestic economic objectives. However, in the context of more open economy, especially with the increasingly large fluctuation extent of exchange rate, how to affect exchange rate by virtue of monetary policy attracts more and more attention of policy makers and investors. However, this issue has not been fully researched.

Most of the existing researches directly analyze the relationship between monetary policy and exchange rate However in recent years with the development of behavioral economics, it is pointed out that investor attention is the premise of investor behavior. Hence, investor attention is an important channel to get exchanged rate affected by monetary policy.

From the perspective of investors' attention to monetary policy, we analyzed the relationship between monetary policy and exchange rate, so as to deepen the understanding of the impact of monetary policy on exchange rate, provide reference for better execution of monetary policy and theoretically provide a new perspective for making exchange rate decision. 


\section{LITERATURE REVIEW}

Since the official establishment of the offshore RMB market in Hong Kong, China, the offshore RMB market has been expanded and the types of offshore business have become richer and richer. The dominant role of RMB exchange rate pricing tends to transfer to offshore market. However, the central bank cannot directly intervene in offshore market, which increases the difficulty in stabilizing the onshore exchange rate Que Chengyu and Ma Bin, 2015). In 2016, RMB's "official participation in the SDR currency basket" promoted the internationalization progress of the RMB so that more international trade and investment will use RMB. Liu Zheng (2017) explained that from the perspective of information structure, currency's participation in SDR may cause changes in capital return and expectations of exchange rate. Caballero \& Krishnamurthy (2006) pointed out that the rapid inflow of international capital is the main reason for increasing the risks in emerging market and countries and causing large fluctuations in exchange rate and other variables. Therefore, it is needed to better understand and master the formation mechanism of the RMB exchange rate and rationally formulate relevant policies to promote smooth operation of economy.

Exchange rate is the market price for transaction between buyer and seller in foreign exchange market and determines the supply and demand relationship with foreign exchange market. It is very difficult to determine the supply and demand function of foreign exchange market and further determine the exchange rate, as the motives of foreign exchange trading are complex and diverse and the factors affecting these motives are even more complicated. Exchange rate determination theory aims to study which factors are the most important variables determining the supply and demand function of foreign exchange and further establish the exact relation between those variables and exchange rate, so as to determine the level of equilibrium exchange rate or predict the change in the real exchange rate. ${ }^{1}$ Traditional exchange rate decision theory includes theory of international indebtedness, purchasing power parity theory, interest rate parity theory, theory of balance of payments and asset market theory and so on. Domestic and foreign scholars have empirically tested the applicability of those theories. The results show that those traditional exchange rate theories cannot be used to predict the exchange rate change in short term. With respect to RMB, Yang Zihui and Chen Chuanglian (2012) pointed out that the Taylor rule (taking interest rate as the dominant factor) could not be permanently used to explain the change in RMB exchange rate; Jin Zhongxia and Chen Hao (2012) pointed out that the interest rate parity theory could not be directly used to explain the change of RMB exchange rate; Bian Xuezi and Fan Aijun (2015) stressed that the impact of monetary policy is not the only cause for short-term exchange rate overshooting. With the continuous development of economic and financial globalization, the limitation of traditional theories becomes more and more

Chen Jiangsheng, et al. Research on RMB exchange rate formation mechanism, Chinese financial\&Economic Publishing House, 2010: 66-67. obvious. Exchange rate theory under the current floating exchange rate system has achieved new development greatly.

Many scholars tried to explain exchange rate change from the behavior level. Frankel and Froot proposed the irrational speculative bubble theory when explaining the phenomenon that USD was continuously overvalued during 1980-1985. This theory assumed that the expectation of economic man is heterogeneous ${ }^{2}$. Burnside et al (2011) used investor overconfidence theory to explain the forward exchange rate premium; Yu (2013) built up an investor sentiment model to explain the mystery of forward exchange rate premium. The above researches all reveal the change of exchange rate in short term from a behavioral perspective. While in this paper, it is intended to make a further research from the perspective of investor attention.

However in field of behavioral finance, the research on investor attention's influence on asset pricing has been becoming mature. People usually choose to focus on specific information consciously as notable information or readily available information is more attractive (Fiske \& Taylor, 1991). Kahneman (1973) proposed the theory of attention cognitive resources, arguing that human attention to one thing would necessarily reduce the attention to other things. Limited attention may restrict people's learning and decision making processes (Pashler \& Johnston, 1998). Thus within certain period, if investor pays attention to an asset, then the price of such asset will be driven by it (Huberman \& Regev, 2001). Nowadays, domestic and foreign researches on investor attention have involved in many fields such as the fluctuation in stock market (Vlastakis \& Markellos, 2012; Cheng Songhao and Zhang Bing, 2014), investor attention and IPO anomaly (Song Shuangjie et al, 2011). , asset pricing research (Shi Rongsheng, 2013) and price drift after earnings announcement (Quan Xiaofeng and Wu Shinong, 2010; Drake et al, 2012).

Although more and more scholars have taken behavioral factors into consideration in studying exchange rate change and taken investor attention into consideration in exploring the asset pricing, few of them made research on exchange rate change in foreign exchange market based on investor attention. Smith (2012) found that prediction on exchange rate fluctuation on the basis of investor attention is better than that on the basis of GARCH $(1,1)$ model, over a research on Australian dollar, Canadian dollar, New Zealand dollar and Swiss franc. Goddard et al. (2015) indicated that investor attention can not only be used to explain the fluctuation of foreign exchange market during the same period but also be used to predict fluctuation of Euro, US dollar, British pound and yen. Yin Libo and Wu You (2017) constructed a multi-dimensional uncertainty attention index and examined its relationship with the RMB exchange rate based on this index, concluded that uncertainty attention index has positive effect on RMB exchange rate.

As can be seen from the above literature, most of domestic and foreign scholars' research on investor attention

Chen Jiangsheng, et al. Research on RMB exchange rate formation mechanism, Chinese financial\&Economic Publishing House, 2010: 83-84 
is based on stock market and asset pricing and so on. There are few special researches focused on investor attention in foreign exchange market. Meanwhile, the contemporary economic and financial situation also prompts us to pay attention to investor attention's influence on exchange rate fluctuation. In addition, central bank of each country must assume the responsibility to maintain the local exchange rate stable. The People's Bank of China can directly participate in foreign exchange market transactions to interfere with RMB exchange rate and can also conduct a macro-control on RMB exchange rate by adjusting domestic interest rate and money supply and other means. There is no doubt that the central bank's monetary policy measures will attract attention of investors in foreign exchange market. But it is wondered whether RMB exchange rate change may be affected after investor searches central bank's monetary policy related information and respond to it effectively. Based on a consideration of this issue, this paper will make a research on the relation between investor attention and dynamic evolution of RMB exchange rate from the aspect of central bank's intervention in the monetary policy to enrich the content of formation mechanism of RMB exchange rate.

\section{MEASUREMENT MODEL: Method AND CONSTRUCTION}

This paper will research the relation between investor attention and dynamic evolution of RMB exchange rate from the aspect of central bank's monetary policy. If the two factors have true simultaneity, it is ought to get two groups of variables applicable to the two factors placed in the same position to research it rather than previously getting one variable classified as endogenous variable and the other one treated as exogenous variable. So, it is considered to use vector auto-regression model (VAR model). The VAR model is a vector generalization form of AR model and studies the dynamic relationship among multiple variables. In addition, considering to use VAR model is also based on the following facts: this model does not take economic and financial theories as a precondition; to some extent, other explanation variables can be added into the model arbitrarily; the model form is flexible; the model has no any prior constraint; It is easy to estimate the parameters of this model; in general, short-term prediction effect of the model is better than that of structural simultaneous equation model; among models used for analyzing and predicting multiple relevant economic variables, VAR model is relatively easy to be operated.

\section{A. Basic Model}

The current variable of each research variable in the VAR model is used as explained variable and several lagged variables of all research variables are used as explaining variables. If it is to research the dynamic relationship among $\mathrm{n}$ variables, the explained variable is an $\mathrm{n}$-dimensional vector. While, in this model equation set, there are $n$ equations.

Basic expression of the VAR model:

$$
\mathrm{Y}_{\mathrm{t}}=\mathrm{C}+\sum_{\mathrm{i}=1}^{\mathrm{k}} \mathrm{A}_{\mathrm{i}} \mathrm{Y}_{\mathrm{t}-\mathrm{i}}+\varepsilon_{\mathrm{t}}
$$

Wherein, $\mathrm{Y}_{\mathrm{t}}$ represents the n-dimensional column vector composed of values of the $\mathrm{t}$-th period of sample; $\mathrm{Ai}$ represents the $n * n$ coefficient matrix, $\varepsilon_{\mathrm{t}}$ represents the $\mathrm{n} * 1$ matrix composed of a random error term; the random error term is a white noise process and $\mathrm{k}$ is lag order.

Control variables, also known as extra correlated variables, are variables beyond the variables researched in the model and having a potential impact on variation of the explained variables. Missing variable may cause endogenous problem. So, it is necessary to add control variable in the model in order to avoid this problem as much as possible and maintain the robustness of the estimated parameters.

The expression after adding the control variable into the model is as follows:

$$
\mathrm{Y}_{\mathrm{t}}=\mathrm{C}+\sum_{\mathrm{i}=1}^{\mathrm{k}} \mathrm{A}_{\mathrm{i}} \mathrm{Y}_{\mathrm{t}-\mathrm{i}}+\sum_{\mathrm{i}=1}^{\mathrm{k}} \mathrm{B}_{\mathrm{i}} \mathrm{Z}_{\mathrm{t}-\mathrm{i}}+\varepsilon_{\mathrm{t}}
$$

Wherein, $\mathrm{Z}_{\mathrm{t}-\mathrm{i}}$ represents the control variable of $\mathrm{i}$ periods lagged, $\mathrm{B}$ is the coefficient and other indexes have the same meaning as above mentioned.

\section{B. Selection of Lag Order}

The setting of VAR model needs to determine the number of lagged periods. The selection of optimal lagged period is mostly judged by the likelihood ratio test or by information criterion. This research adopted the second test method. The operation of VAR model lag period test in software Eviews, by observing the values of SC, HQ, LR, AIC and FPE given up to the 15th order, it is found that the lag order selected on the basis of three criterions is 4th order according to the values of SC, HQ, LR, AIC and FPE provided to the 15 th order by observation. On the basis of "majority principle", the lag order of VAR model established in this study is determined as 4th order.

\section{DESCRIPTION OF VARIABLES AND DATA}

\section{A. Research Variables}

First of all, with respect to RMB exchange rate, the central parity of the RMB against the US dollar is the most important exchange rate index in the spot inter-bank foreign exchange market and thus is selected as the research object of RMB exchange rate (CNY) in this paper. Daily data of the index can be obtained from official website of the People's Bank of China.

Second, investor attention index based on monetary policy is constructed in this paper as there is not directly available investor attention data in major websites and various databases. Since proxy variables that investor pays attention to may contain information irrelevant to investor attention and some proxy variables cannot be ensured to be noticed by investors, Da et al. (2011) proposed a new way to directly measure investor attention. That is to use the aggregate search frequency in Google Trends, take the obtained search volume index (SVI) as the measure of attention and then research the relation between investor attention and asset price. The empirical results confirm that SVI can effectively explain the stock price increase and IPO 
anomaly in short term. Because Baidu dominates the market in the Chinese search engine market, Zhang Yihao et al (2014) used the Baidu Index to measure investor attention. The result indicates that investor attention may indeed affect the short-term yield of stock market; Chen et al (2016) also used the Baidu Index to measure investor attention. The empirical results show that investor attention is increased significantly when consumer price index is released and may affect the price and fluctuation of Chinese stock index futures in short term. This indicates that as an outward manifestation of investor attention, the search volume can be directly used to measure the level of investor attention. Thereby in this paper, investor attention is measured by the Baidu index with reference to this method.

In order to establish the investor attention index, the following steps were conducted: browse the exchange rate and currency related contents on the websites of the People's Bank of China, China Foreign Exchange Network, China Money Network, etc., pay special attention to the monetary policy available to be adopted by the central bank to intervene in exchange rate, initially select and search several main keywords, then eliminate some entries not recorded by Baidu Index or existing ambiguity by screening in combination with relevant search results provided by Baidu. Finally, 9 keywords were determined, respectively RMB exchange rate, central bank, foreign exchange reserves, money supply, monetary policy, deposit reserve ratio, central bank benchmark interest rate, standing lending facility, central bank interest rate reduction. Then, since the Baidu Index currently supports a combination of at most three keywords connected by "+" to get the accumulated search volume, the investor attention index in this paper was obtained by dividing the nine keywords into three groups and then having the sum of search volume indexes of the three groups of combined words divided by 9 to get the average value.

The starting and ending times of all data stated in this paper is from Oct.29, 2015 to Dec.30, 2017. Finally 508 data samples were obtained by adopting daily data and eliminating any mismatched part between all variable data involved in this research. In addition, the data processing and empirical analysis stated in this paper were carried out by using softwares Excel 2010 and Eviews 6.0.

\section{B. Control Variables}

1) Interest rate parity: In the earliest time, what interest rate parity theory explored is the change in exchange rate from the perspective of capital flow and and the theory believes that the difference in interest rate can stimulate the flow of short-term capital in international market. After adding friction coefficient into Chinese interest rate parity model and get the model modified, Yi Gang et al (1997) found that the coefficient of friction determined by the system tended to be zero with the unceasing improvement of the extent of reform and opening up. Fan Lifu et al (2010) pointed out that interest rate parity theory had practical guiding significance for the current exchange rate policy in China.
In addition in this paper, monetary policy was regarded as control variable considering that exchange rate may be affected by investor attention as indicated in the model result for reason of not investor attention itself but monetary policy influence. Moreover interest rate is used as proxy variable of monetary policy, as interest rate is the intermediate index of monetary policy and the change in interest rate reflects the change in tightness of monetary policy. Therefore in this research, interest rate parity was added to the model to serve as a control variable and Sino-US bond spread was used to represent the interest rate parity index. The expression is:

$$
\mathrm{I}_{\mathrm{t}}=\mathrm{i}_{\mathrm{dt}}-\mathrm{i}_{\mathrm{ft}}
$$

Wherein, $I_{t}$ represents the Sino-US bond spread in the $t$ th period, $i_{d t}$ represents the yield of China Treasury bond in the three months of the $\mathrm{t}$-th period and ${ }^{\mathrm{i}} \mathrm{ft}$ represents the yield of US Treasury bond in the three months of the $\mathrm{t}$-th period.

2) Liquidity: Capital liquidity also has large influence on exchange rate of a country. Chen Chuanglian et al (2012) believed that capital flow may change the risk premium of foreign currency held and the empirical result proves that the risk premium shock can be used to explain partial fluctuation of RMB exchange rate. This indicates that capital flow is an important factor affecting exchange rate fluctuation. Therefore in this paper, liquidity was used as a control variable to measure liquidity and the liquidity was measured on the basis of TED spread (TED). TED spread was calculated by getting the three-month European dollar yield deducted by three-month US Treasury yield. This index is used to reflect the tightness of global liquidity and is a common index in international financial market. Increase of TED spread indicates that the market risk is expanding and the liquidity of capital in the market tends to be tightened, causing increase in borrowing costs of both bank and enterprise. This indicates that the credit situation is tightening. So, the global liquidity will tend to be tightened.

The three-month US Treasury yield data used in this research was soured from official website of The Federal Reserve. The three-month European dollar yield data was sourced from the Wind Information Financial Terminal. Then daily TED spread data was calculated as per the said definition of TED.

3) Expectation: Expectation is also one of the important factors affecting exchange rate price because it is characterized by self-realization and enhancement. If most investors in foreign exchange market expect that the value of a currency will fall, they will take action to immediately sell the currency. A large supply will cause reduction in value of the currency. At this time, the foreign exchange market may show the expected self-realization, which makes investors further confirm their judgment, causing self-enhancement in the market. Therefore, expectation should be considered as a control variable.

Ren Zhaozhang and Ning Zhongzhong (2005), over empirical analysis, found that the fluctuation of RMB NDF 
exchange rate is consistent with the expectation of foreign exchange market for RMB exchange rate and hence they used NDF exchange rate as an expected variable. Ye Xin et al (2012) and Bai Xiaoyan et al (2014) also empirically proved that it is appropriate to use RMB forward exchange rate as a proxy variable for the $\mathrm{RMB}$ exchange rate expectation. Therefore, the purchase and quotation price of USD-to-RMB forward exchange rate in three months was selected as a proxy variable of expectation. This variable sequence name was recorded as FXA and the data was obtained from Wind.

\section{Variable Stability Test}

When analyzing economic and financial data, the horizontal value of the variable is usually not used, because the measurement unit of each variable is not conducive to making comparative analysis, or the original value is so large that the calculated value may be beyond the range of commonly used data. So, selecting logarithm can reduce the original value and may not change the correlation and statistical properties of the data. But compressing the variable scale can make the data more stable, and can also weaken the heteroscedasticity and collinearity of the model. Most time sequences in practical application are not stable. The unstable trend contained in the sequence is usually eliminated by difference method and the model is established only after the sequence becomes stable. What discussed in this paper is the sequence of logarithm corresponding to each variable after subjecting to difference processing in order to reduce the fluctuation and heteroscedasticity. With respect to the VAR model, non-stable sequence can be used directly if it is to research whether there is a long-term equilibrium relationship between the variables; stable time sequence should be used if it is to explore short-term relations between the variables. This paper mainly studies the short-term relationship between RMB exchange rate and investor attention. So, a stability test was conducted on sequence of each variable after subjecting to logarithmic difference processing.

In this study, the corresponding sequence names of middle RMB-to-USD exchange rate, investor attention index, the Sino-US bond spread, TED spread and USD-to-RMB forward exchange rate after subjecting to logarithmic difference processing were respectively recorded as $\mathrm{CNY}$, ATT, I, TED and FXA. Sequences of the five variables were respectively conducted $\mathrm{ADF}$, ADF unit root test for these five variable sequences in Eviews6.0 software, the results show that the corresponding $\mathrm{t}$ statistics are less than the critical values of unit root test under $1 \%, 5 \%$ and $10 \%$ confidence levels. Therefore, the original hypothesis should be rejected. Namely, sequence of each variable sequence is stable sequence.

\section{Descriptive Statistical Analysis}

"Table I" shows the descriptive statistic results of RMB exchange rate, investor attention index and control variables that have all been subjected to logarithmic difference processing. As is known from "Table I", (1) the average change rate of RMB exchange rate is positive, which indicates that the middle price of RMB against US dollar is generally depreciated during the sample period. This is in line with the real status. The average value of investor attention index is also positive, indicating that investor attention has an overall upward trend during the sample period. (2) By observing the kurtosis and skewness values of each variable, it is found that most of the sequences exhibit the characteristics of "sharp peak and heavy tail". (3) The JB statistic of each variable is very large and value $\mathrm{P}$ is also 0 almost, which indicates that no sequence is in normal distribution. (4) The standard deviation of each sequence is very small, which indicates that its fluctuation extent is small and also confirms the results of the previous unit root test, that is, each sequence after subjecting to logarithm difference processing is stable.

TABLE I. Descriptive Statistical Characteristics of EACH SEQUENCE

\begin{tabular}{|l|l|l|l|l|l|l|l|l|}
\hline Variable & \multicolumn{1}{|c|}{ Average } & $\begin{array}{l}\text { Standard } \\
\text { deviation }\end{array}$ & \multicolumn{1}{|c|}{ Median } & \multicolumn{1}{|c|}{ Max. } & \multicolumn{1}{|c|}{ Min. } & Kurtosis & Skewness & \multicolumn{1}{|c|}{ JB statistic } \\
\hline CNY & 0.0001 & 0.0022 & 0.0001 & 0.0091 & -0.0093 & 2.0876 & -0.1821 & 95.18 \\
\hline ATT & 0.0006 & 0.1511 & -0.0138 & 1.2178 & -0.6369 & 15.0844 & 2.2196 & 5119.03 \\
\hline I & 0.0002 & 0.0343 & -0.0010 & 0.4330 & -0.3973 & 85.5143 & 0.9988 & 151498.7 \\
\hline TED & 0.0003 & 0.1542 & -0.0005 & 2.1382 & -2.1079 & 141.723 & 0.2277 & 415934.7 \\
\hline FXA & -0.0002 & 0.0661 & 0.0000 & 0.4212 & -0.3019 & 5.4600 & 0.2389 & 619.54 \\
\hline
\end{tabular}

\section{EMPIRICAL RESULTS AND ANALYSIS}

\section{A. Results of Benchmark Model}

The specific benchmark model of this research is expressed as follows:

$$
\begin{aligned}
& C N Y_{t}=C+\sum_{i=1}^{4} \alpha_{i} C N Y_{t-i}+\sum_{i=1}^{4} \beta_{i} A T T_{t-i}+\varepsilon_{t} \\
& A T T_{t}=C+\sum_{i=1}^{4} \alpha_{i} C N Y_{t-i}+\sum_{i=1}^{4} \beta_{i} A T T_{t-i}+\varepsilon_{t}
\end{aligned}
$$

Wherein, $\alpha$ and $\beta$ are the coefficients to be evaluated; $C N Y_{t-i}$ indicates the RMB exchange rate index of $i$ lagged period(s); $A T T_{t-i}$ indicates the investor attention index of $\mathrm{i}$ lagged period(s). The other index has the same meaning as aforesaid.

The model results are listed in "Table II". As can be observed, when the lag period is 4 periods, the influence of the investor attention index on RMB exchange rate from perspective of monetary policy of central bank is obviously 
positive. This indicates that the increase in investor attention index may cause increase in growth rate of RMB exchange rate. In addition, the fluctuation of RMB exchange rate is not a key factor in determining the change in investor attention index.

TABLE II. VAR MODEL RESUlts BETWEEN RMB EXCHANGE RATE AND INVESTOR ATTENTION INDEX

\begin{tabular}{|l|l|l|}
\hline & \multicolumn{1}{|c|}{ CNY } & \multicolumn{1}{c|}{ ATT } \\
\hline CNY(-1) & $-0.077284 *$ & 2.368452 \\
\hline & $(0.04476)$ & $(3.05347)$ \\
\hline CNY(-2) & -0.012508 & -1.170916 \\
\hline & $(0.04485)$ & $(3.05933)$ \\
\hline CNY(-3) & 0.024214 & -1.041742 \\
\hline & $(0.04484)$ & $(3.05911)$ \\
\hline CNY(-4) & 0.062286 & 1.261115 \\
\hline & $(0.04460)$ & $(3.04252)$ \\
\hline ATT(-1) & $0.001309 * *$ & $-0.23153 * * *$ \\
\hline ATT(-2) & 0.001017 & $(0.04483)$ \\
\hline & $(0.00067)$ & $-0.124124 * * *$ \\
\hline ATT(-3) & 0.000626 & $(0.04600)$ \\
\hline & $(0.00068)$ & $-0.095075 * *$ \\
\hline ATT(-4) & $0.001359 * *$ & $(0.04606)$ \\
\hline & $(0.00066)$ & $-0.092057 * *$ \\
\hline C & 0.000059 & $0.004504)$ \\
\hline & $(0.00009)$ & $(0.00661)$ \\
\hline
\end{tabular}

a. Note: (1) CNY(i) in the table indicates the RMB exchange rate after subjecting to logarithmic difference processing with $\mathrm{i}$ lagged period(s) and ATT(i) indicates the attention index after difference processing with i lagged period(s) and ATT(i) indicates the attention index after subjecting to logarithmic difference processing with ilagged period(s), (2) the output result in the table is dividion model and the standard deviation of the estimated coefficients (i.e, he values in parentheses);

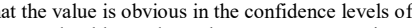
$1 \%, 5 \%$ and $10 \%$; (4) Table IV and Table $\mathrm{V}$ adopts the same representations.

\section{B. Granger Causality Test}

The Granger causality test is method for analyzing the causal relationship between variables and is invented by Clive Granger. In this test process, Eviews can be used to create a VAR model and then select the item "Granger Causality Test" and accept the original hypothesis if the probability value $\mathrm{P}$ is greater than the confidence level and if not, reject the original hypothesis. "Table III" shows the results of the Granger causality test. As can be found from the table, provided that there are 4 lagged periods, the probability value $\mathrm{P}$ is 0.003 , less than the confidence level (0.05), so the null hypothesis "Investor attention is not the Granger cause of exchange rate" is rejected. That is to say, from the perspective of monetary policy, investor attention is the cause affecting fluctuation of RMB exchange rate, while the fluctuation of RMB exchange rate is not the cause for change in investor attention index. The result is consistent with the results shown in "Table II", indicating that investor attention index can be used to raise the ability to predict RMB exchange rate.
TABLE III. GRANGER CAUSALITY TEST BETWEEN RMB EXCHANGE RATE AND INVESTOR ATTENTION INDEX

\begin{tabular}{|l|l|l|l|l|}
\hline Zero hypothesis & $\begin{array}{c}\text { Lagged } \\
\text { period }\end{array}$ & $\begin{array}{c}\text { Statistic } \\
\text { F }\end{array}$ & $\begin{array}{c}\text { Probability } \\
\text { value P }\end{array}$ & Conclusion \\
\hline $\begin{array}{l}\text { ATT is not the } \\
\text { Granger cause of } \\
\text { CNY }\end{array}$ & 4 & 15.362 & 0.003 & Reject \\
\hline $\begin{array}{l}\text { CNY is not the } \\
\text { Granger cause of } \\
\text { ATT }\end{array}$ & 4 & 0.232 & 0.892 & Accept \\
\hline
\end{tabular}

\section{Impulse Response Function}

The VAR result in "Table II" reflects local dynamic relationship of the model from the coefficient level. Impulse response function was adopted in this research in order to research the full impacts of investor attention index change on RMB exchange rate. The impulse response function of RMB exchange rate against unit impact of investor attention index unit from the monetary policy level is as shown in "Fig. 1 ". In case of subjecting to impact of one unit of investor attention, RMB exchange rate may immediately give response positively, the influence of investor attention on $\mathrm{RMB}$ exchange rate may last for long time, the impact effect does not change until after the seventh period and returns to original value until the 11th period. As can be seen from "Fig. 2 ", the response fluctuation of investor attention against the impact of exchange rate is gentle and the impact of exchange rate on investor attention is not significant.

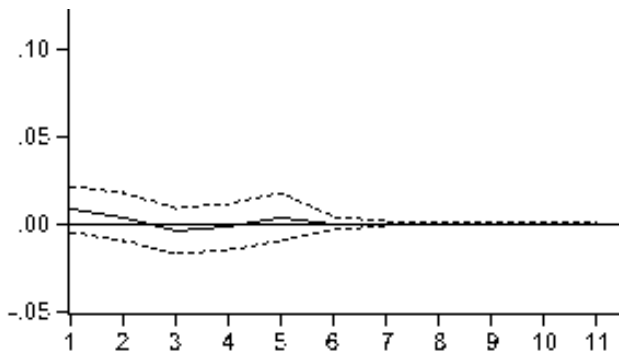

Fig. 1. The impulse response of exchange rate to investor attention.

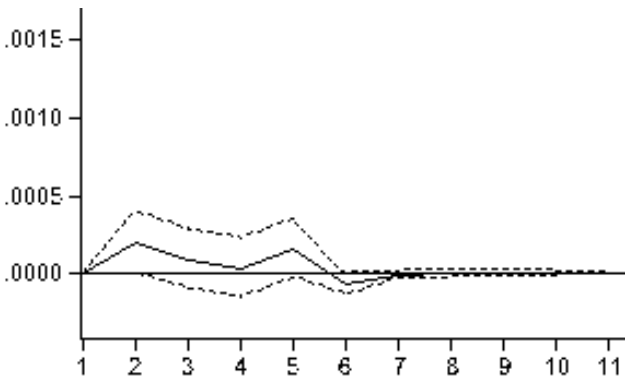

Fig. 2. The impulse response of investor attention to exchange rate

\section{Adding Control Variables}

The specific model after adding control variables onto the aforementioned model is as follows:

$\mathrm{CNY}_{\mathrm{t}}=\mathrm{C}+\sum_{\mathrm{i}=1}^{4} \alpha_{\mathrm{i}} \mathrm{CNY}_{\mathrm{t}-\mathrm{i}}+\sum_{\mathrm{i}=1}^{4} \beta_{\mathrm{i}} \mathrm{ATT}_{\mathrm{t}-\mathrm{i}}+\sum_{\mathrm{i}=1}^{4} \gamma_{\mathrm{i}} \mathrm{CON}_{\mathrm{t}-\mathrm{i}}+\varepsilon_{\mathrm{t}}$ 


$$
\operatorname{ATT}_{\mathrm{t}}=\mathrm{C}+\sum_{\mathrm{i}=1}^{4} \alpha_{\mathrm{i}} \mathrm{CNY}_{\mathrm{t}-\mathrm{i}}+\sum_{\mathrm{i}=1}^{4} \beta_{\mathrm{i}} \mathrm{ATT}_{\mathrm{t}-\mathrm{i}}+\sum_{\mathrm{i}=1}^{4} \gamma_{\mathrm{i}} \mathrm{CON}_{\mathrm{t}-\mathrm{i}}+\varepsilon_{\mathrm{t}}
$$

Wherein, $\mathrm{CON}_{\mathrm{t}-\mathrm{i}}$ represents the change rate of the control variable index over i lagged period (s) and can be expressed

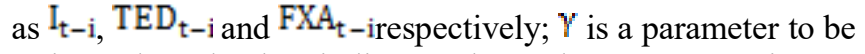
estimated, and other indicators have the same meaning as aforesaid.

"Table IV" shows the VAR results between RMB exchange rate and investor attention index after introducing interest rate parity, liquidity and expectation as control variables. By comparing "Table II" with 4-1 in "Table IV", it can be found that under the optimal condition of 4 lagged periods, the symbol of investor attention coefficient after adding Sino-US bond spread is positive and significant. This feature is the same as that before adding interest rate parity index but only small change in value. This indicates that interest rate parity does not cover the information contained in investor attention and investor attention can effectively affect the change of RMB exchange rate. Therefore, it is beneficial to improve the effectiveness of interest rate parity in pricing mechanism of RMB exchange rate if the People's Bank of China getting investor attention added into interest rate parity mechanism when formulating monetary policy. By observing and analyzing "Table II" and 4-2 in "Table IV", it can be found that there is no change in symbol and significance of investor attention coefficient after adding TED spread as a control variable. This indicates that the information reflected in investor attention is not covered by the liquidity and investor attention's influence on exchange rate change is independent of the effect of liquidity. Therefore, when studying the relationship between liquidity and exchange rate, the monetary authorities should take investor attention into consideration and reasonably and effectively guide investor attention so as to achieve the policy objectives. Comparing "Table II" with 4-3 in "Table IV", the symbols of investor attention coefficients are the same and both significant. Above all, the main conclusions of this paper are not changed for reason of adding the said control variables. That is to say, investor attention index at the monetary policy level still significantly and positively affects the RMB exchange rate and the influence extent is not changed largely for reason of the adding of the said control variables.

TABLE IV. VAR RESULTS BETWEEN RMB EXCHANGE RATE AND INVESTOR ATTENTION INDEX AFTER ADDING CONTROL VARIABLES

\begin{tabular}{|l|l|l|}
\hline \multicolumn{3}{|c|}{ 4-1. Taking Sino-US bond spread I as a control variable } \\
\hline & CNY & \multicolumn{1}{c|}{ ATT } \\
\hline CNY(-1) & $-0.074689^{*}$ & 2.513622 \\
\hline & $(0.04495)$ & $(3.07477)$ \\
\hline CNY(-2) & -0.007496 & -0.876883 \\
\hline & $(0.04514)$ & $(3.08758)$ \\
\hline CNY(-3) & 0.028815 & -0.902933 \\
\hline & $(0.04516)$ & $(3.08864)$ \\
\hline CNY(-4) & 0.065520 & 1.272788 \\
\hline & $(0.04482)$ & $(3.06573)$ \\
\hline ATT(-1) & $0.001359^{* *}$ & $-0.229247^{* * *}$ \\
\hline & $(0.00066)$ & $(0.04504)$ \\
\hline ATT(-2) & 0.001064 & $-0.121538^{* * *}$ \\
\hline
\end{tabular}

\begin{tabular}{|c|c|c|}
\hline & CNY & ATT \\
\hline & $(0.00068)$ & $(0.04625)$ \\
\hline \multirow{2}{*}{ ATT(-3) } & 0.000671 & $-0.094035^{* *}$ \\
\hline & $(0.00068)$ & $(0.04633)$ \\
\hline \multirow[t]{2}{*}{ ATT(-4) } & $0.001353^{* *}$ & $-0.093304 * *$ \\
\hline & $(0.00066)$ & $(0.04527)$ \\
\hline \multirow[t]{2}{*}{$\mathrm{I}(-1)$} & $-0.005827^{*}$ & -0.236312 \\
\hline & $(0.00298)$ & $(0.20373)$ \\
\hline \multirow[t]{2}{*}{$\mathrm{I}(-2)$} & -0.002259 & -0.063591 \\
\hline & $(0.00314)$ & $(0.21491)$ \\
\hline \multirow[t]{2}{*}{$\mathrm{I}(-3)$} & -0.001452 & 0.033819 \\
\hline & $(0.00314)$ & $(0.21488)$ \\
\hline \multirow[t]{2}{*}{$\mathrm{I}(-4)$} & -0.000541 & 0.020353 \\
\hline & $(0.00299)$ & $(0.20433)$ \\
\hline \multirow[t]{2}{*}{$\mathrm{C}$} & 0.000061 & 0.000808 \\
\hline & $(0.00009)$ & $(0.00663)$ \\
\hline \multicolumn{3}{|c|}{ 4-2. Taking TED spread as a control variable } \\
\hline & CNY & $\begin{array}{l}\text { ATT } \\
\end{array}$ \\
\hline \multirow[t]{2}{*}{ CNY(-1) } & $-0.083075^{*}$ & 2.687978 \\
\hline & $(0.04493)$ & $(3.07942)$ \\
\hline \multirow[t]{2}{*}{$\mathrm{CNY}(-2)$} & -0.005773 & -1.074833 \\
\hline & $(0.04509)$ & $(3.09009)$ \\
\hline \multirow[t]{4}{*}{$\mathrm{CNY}(-3)$} & 0.033582 & -1.131985 \\
\hline & $(0.04508)$ & $(3.08976)$ \\
\hline & 0.065809 & 1.217945 \\
\hline & $(0.04468)$ & $(3.06229)$ \\
\hline \multirow{2}{*}{ ATT(-1) } & $0.001245^{*}$ & $-0.22843^{* * *}$ \\
\hline & $(0.00066)$ & $(0.04504)$ \\
\hline \multirow[t]{2}{*}{ ATT(-2) } & 0.001004 & $-0.123277 * * *$ \\
\hline & $(0.00067)$ & $(0.04616)$ \\
\hline \multirow[t]{2}{*}{ ATT(-3) } & 0.000635 & $-0.095725^{* *}$ \\
\hline & $(0.00067)$ & $(0.04621)$ \\
\hline \multirow[t]{2}{*}{ ATT(-4) } & $0.001410 * *$ & $-0.090334^{* *}$ \\
\hline & $(0.00066)$ & $(0.04508)$ \\
\hline \multirow[t]{2}{*}{ TED(-1) } & $-0.002015^{* * *}$ & -0.056363 \\
\hline & $(0.00071)$ & $(0.04882)$ \\
\hline TED(-2) & -0.001237 & 0.032466 \\
\hline & $(0.00081)$ & $(0.05543)$ \\
\hline TED(-3) & -0.000609 & -0.015244 \\
\hline & $(0.00081)$ & $(0.05562)$ \\
\hline TED(-4) & -0.000104 & -0.006128 \\
\hline & $(0.00072)$ & $(0.04934)$ \\
\hline $\mathrm{C}$ & 0.000059 & 0.000793 \\
\hline & $(0.00009)$ & $(0.00662)$ \\
\hline 4-3. Takin & ectation FXA as & control variable \\
\hline & CNY & ATT \\
\hline CNY(-1) & $-0.081402 *$ & 2.572538 \\
\hline & $(0.04488)$ & $(3.03632)$ \\
\hline $\mathrm{CNY}(-2)$ & -0.015811 & -1.186805 \\
\hline & $(0.04495)$ & $(3.04097)$ \\
\hline $\mathrm{CNY}(-3)$ & 0.025422 & -1.667276 \\
\hline & $(0.04494)$ & $(3.04005)$ \\
\hline CNY(-4) & 0.068518 & 0.705925 \\
\hline & $(0.04471)$ & $(3.02487)$ \\
\hline ATT(-1) & $0.001519^{* *}$ & $-0.249752 * * *$ \\
\hline & $(0.00067)$ & $(0.04504)$ \\
\hline ATT(-2) & $0.001201^{*}$ & $-0.130831 * * *$ \\
\hline & $(0.00069)$ & $(0.04636)$ \\
\hline ATT(-3) & 0.000719 & $-0.093212^{* *}$ \\
\hline & $(0.00068)$ & $(0.04609)$ \\
\hline ATT(-4) & $0.001385 * *$ & $-0.090195^{* *}$ \\
\hline & $(0.00066)$ & $(0.04469)$ \\
\hline FXA(-1) & 0.000357 & $-0.259455^{* *}$ \\
\hline
\end{tabular}




\begin{tabular}{|l|c|c|}
\hline & CNY & ATT \\
\hline & $(0.00151)$ & $(0.10235)$ \\
\hline FXA(-2) & $0.002986^{*}$ & $-0.276516^{* * *}$ \\
\hline & $(0.00153)$ & $(0.10369)$ \\
\hline FXA(-3) & 0.001180 & -0.132648 \\
\hline & $(0.00152)$ & $(0.10286)$ \\
\hline FXA(-4) & 0.001784 & -0.004166 \\
\hline C & $(0.00151)$ & $(0.10243)$ \\
\hline & 0.000057 & 0.001080 \\
\hline & $(0.00009)$ & $(0.00655)$ \\
\hline
\end{tabular}

TABLE V. VAR RESUlT BETWEEN INVESTOR ATTENTION AND RMB EXCHANGE RATE AFTER AdDing All CONTROL VARIABLES

\begin{tabular}{|l|l|l|}
\hline & \multicolumn{1}{|c|}{ CNY } & \multicolumn{1}{c|}{ ATT } \\
\hline CNY(-1) & $-0.088943 * *$ & 2.652697 \\
\hline & $(0.04529)$ & $(3.05863)$ \\
\hline CNY(-2) & -0.008763 & -0.65649 \\
\hline & $(0.04540)$ & $(3.06622)$ \\
\hline CNY(-3) & 0.036742 & -2.168202 \\
\hline & $(0.04543)$ & $(3.06810)$ \\
\hline CNY(-4) & $0.074554^{*}$ & 0.695249 \\
\hline & $(0.04512)$ & $(3.04740)$ \\
\hline ATT(-1) & $0.001445^{* *}$ & $-0.23901 * * *$ \\
\hline & $(0.00068)$ & $(0.04574)$ \\
\hline ATT(-2) & $0.001172 *$ & $-0.119205 * *$ \\
\hline & $(0.00069)$ & $(0.04690)$ \\
\hline ATT(-3) & 0.000777 & $-0.096672 * *$ \\
\hline & $(0.00069)$ & $(0.04630)$ \\
\hline ATT(-4) & $0.001505^{* *}$ & $-0.081621 *$ \\
\hline & $(0.00067)$ & $(0.04497)$ \\
\hline
\end{tabular}

After adding three control variables respectively, investor attention still has significant influence on RMB exchange rate. So, can investor attention still pose effect independently if those variables are added to the benchmark model at the same time? By comparing "Table V" with "Table II", it is found that after adding all the control variables into the model at the same time, investor attention's influence on $\mathrm{RMB}$ exchange rate is significant and positive. This indicates that investor attention can independently pose effect on RMB exchange rate.

\section{CONCLUSION}

In order to explore the relationship between investors' investment behavior and RMB exchange rate change after investors pay attention to monetary policy, the following steps were carried out for this paper: construct indices, select variables, collect data, build model and conduct empirical analysis. The result shows that: first, investor attention index at the monetary policy level has positive effect on change of RMB exchange rate. Second, investor attention's influence on change of RMB exchange rate is still significant after taking interest rate parity, liquidity and expectation as control variables in this paper. This indicates that the existing pricing mechanism does not cover the information contained in investor attention.

The main contribution of this research is that it introduces investor attention at monetary policy level into the analysis of RMB exchange rate change, proves that investor attention may positively and significantly affect the fluctuation of RMB exchange rate by conducting empirical analysis and provides a new idea for the central bank to stabilize the exchange rate; At the same time, it also proves that investor attention involves information that is not covered by traditional economic variable and can provide valuable suggestions for the central bank to realize more effective control on exchange rate.

According to the conclusions drawn from this study, the following enlightenment can be drawn: first, in order to adjust and stabilize RMB exchange rate by formulating monetary policy, the People's Bank of China needs to take into consideration of the foreign exchange investors' attention on monetary policy and possible investment behavior. Second, the central bank should construct an investor attention index on monetary policy and predict the change of RMB exchange rate based on changes in this index so as to facilitate taking countermeasures in time. Third, foreign exchange investors should correctly interpret monetary policy, use RMB attention index to predict the fluctuation of exchange rate and adopt a rational investment strategy to achieve the expected returns.

There are some shortcomings in the research process of this paper. It is thought that some important keywords are not recorded by Baidu Index so that it is not available to obtain their search volume data. In addition, the main module of Baidu Index not only involves the trend of single keyword but also involves the overall trend based on an industry. It also gives the geographical distribution and population attributes of each keyword. However, that information was not further researched in this paper. The research effect might be better if the analysis can be detailed.

\section{REFERENCES}

[1] Bai Xiaoyan, Guo Yu. Research on fluctuation features of RMB exchange rate expectation before and after exchange rate reforming [J]. Studies of International Finance, 2014 (06): 31-39. (in Chinese)

[2] Bian Xuexue, Fan Aijun. Noise trade, trade opening and lagged exchange rate overshooting - a theoretical research based on PTMNOEM model [J]. Nankai Economic Studies, 2015 (04): 23-43. (in Chinese)

[3] Chen Chuanglian, Yang Zihui. Taylor rule, capital mobility and rea exchange rate fluctuations [J]. Journal of Financial Research, 2012 (11): 60-73. (in Chinese)

[4] Cheng Songhao, Zhang Bing. Limited attention behavior and IPO performance of investors - a research based on Baidu Index [J]. Journal of Guangdong University of Finance, 2014 (6). (in Chinese)

[5] Fan Lifu, Zhou Jiyan. Analysis of interest rate parity theory [J] Economy and Management, 2010, 24 (08): 79-83. (in Chinese)

[6] Jin Zhongxia, Chen Hao. Realization form of interest rate parity theory in China [J]. Journal of Financial Research, 2012 (7): 63-74. (in Chinese)

[7] Liu Zheng. International capital flows, exchange rate and expectation management: the effect analysis of including the RMB in the SDR 
basket [J]. Journal of Central University of Finance \& Economics, 2017 (4): 117-128. (in Chinese)

[8] Quan Xiaofeng, Wu Shinong. Investor attention, post-earningsannouncement drift and management announcement time selection [J]. Journal of Financial Research, 2010 (11). (in Chinese)

[9] Que Chengyu, Mabin. Asymmetric spillover effect of onshore and offshore market exchange rate of RMB - empirical envidence based on VAR-GJR-MGARCH-BEKK model [J]. Studies of International Finance, 2015 (7): 21-32. (in Chinese)

[10] Ren Zhaozhang, Ning Zhongzhong. An empirical study of CNY exchange rate expectation and NDF rate[J]. Academic Research, 2005 (12): 34-39. (in Chinese)

[11] Shi Rongsheng. Asset pricing based on investor attention [D]. Shanghai Jiao Tong University, 2013. (in Chinese)

[12] Song Shuangjie, Cao Hui, Yang Kun. Investor attention and IPO anomaly - empirical envidence based on network search volume $[\mathrm{J}]$. Economic Research Journal, 2011, 46 (S1): 145-155. (in Chinese)

[13] Ye Xin, Chen Weizhong, Sun Lihua. A regime-switching approach for identifying abnormal fluctuation of RMB non-deliverable forward exchange rate $[\mathrm{J}]$. Journal of Tongji University (natural science), 2012, 40 (12): 1894-1898. (in Chinese)

[14] Yi Gang, Fan Min. Decisive factors of RMB exchange rate and the trend [J]. Economic Research Journal, 1997, 32 (10): 26-35. (in Chinese)

[15] Yi Libo, Li Bo. A study on the impact of investor attention on RMB exchange rate spread - based on the GARCH-MIDAS model [J]. Journal of Management Science, 2017, 30 (5): 147-159. (in Chinese)

[16] Yi Libo, Wu You. Dynamic evolution of uncertain impact aqnd RMB exchange rate - from the perspective of investor attetnion [J].Journal of Guangdong University of Finance, 2017, 32 (02): 3-19. (in Chinese)

[17] Yi Libo, Wu You. Investor attention and RMB exchange rate price trend [J]. Tsinghua financial review, 2017, (02): 69-72. (in Chinese)

[18] Zhang Yihao, Li Yuan, Su Zhongfeng. Can internet search predict the stock market? [J]. Journal of Financial Research, 2014 (2): 193-206. (in Chinese)

[19] Burnside C, Han B, Hirshleifer D, et al. Investor overconfidence and the forward premium puzzle. The Review of Economic Studies, 2011, 78 (2): 523-558.

[20] Caballero R J, Krishnamurthy A. Bubbles and capital flow volatility: Causes and risk management [J]. Journal of Monetary Economics, 2006, 53 (1): 35-53.

[21] Chen J, Liu Y J, Lu L, et al. Investor attention and macroeconomic news announcements: evidence from stock index futures [J]. Journal of Futures Markets, 2016, 36 (3): 240-266.

[22] Drake M S, Roulstone D T, Thornock J R. Investor information demand: evidence from Google searches around earnings announcements [J]. Social Science Electronic Publishing, 2012, 50 (4): 1001-1040

[23] Fiske, S.T., Taylor, S.E. Social cognition [M]. Mcgraw-Hill Book Company, 1991.

[24] Huberman G, Regev T. Contagious speculation and a cure for cancer: a nonevent that made stock prices soar [J]. Journal of Finance, 2001, 56 (1): 387-396.

[25] John Goddard, Arben Kita, Qingwei Wang. Investor attention and FX market volatility [J]. Journal of International Financial Markets, Institutions \& Money, 2015, 38: 79-96.

[26] Kahneman, D. Attention and effort [M]. Prentice-Hall, 1973.

[27] Pashler H, Johnston J C. Attentional limitations in dual-task performance [J]. H Pashler Attention, 1998.

[28] Smith G P. Google Internet search activity and volatility prediction in the market for foreign currency [J]. Finance Research Letters, 2012, 9 (2): $103-110$

[29] Vlastakis N, Markellos R N. Information demand and stock market volatility [J]. Social Science Electronic Publishing, 2012, 36 (6): 1808-1821.

[30] Yu J. A sentiment-based explanation of the forward premium puzzle. Journal of Monetary Economics, 2013, 60 (4): 474-491.
[31] Zhi D A, Engelberg J, Gao P. In search of attention [J]. Journal of Finance, 2011, 66 (5): 1461-1499. 